\title{
RESENHA
}

\section{PESQUISA EDUCACIONAL SOBRE REPRESENTAÇÕES SOCIAIS: o uso da técnica do desenho e dos mapas conceituais}

\author{
Angélica Maria Lins dos Santos' \\ Kátia Maria dos Santos Dias²
}

\begin{abstract}
OLIVEIRA, I. A. de; OLIVEIRA, W. M. M. de; LOBATO, H. K. G. (Orgs). Pesquisa Educacional sobre Representações Sociais: O uso da técnica do desenho e dos mapas conceituais. São Carlos. Pedro\&João Editores. 2018. 89p. ISBN 978-85-7993480-3.
\end{abstract}

Lançado em 2018, pela Pedro\&João Editores, o livro "PESQUISA EDUCACIONAL SOBRE REPRESENTAÇÕES SOCIAIS: O uso da técnica do desenho e dos mapas conceituais" surgiu de estudos desenvolvidos pelos pesquisadores a partir do aporte teórico metodológico da pesquisa de mestrado dos autores com seus orientadores. Esta obra discorre sobre a Teoria das Representações Sociais voltada para o campo educacional, e destaca as técnicas do desenho e os mapas conceituais que podem ser associados nas pesquisas de Representações Sociais.

Logo na apresentação do livro é possível constatar que as representações sociais vêm sendo trabalhadas em diferentes áreas da educação com destaque para a educação infantil, educação de jovens e adultos, educação especial, com bastante sucesso. Sendo possível identificar que a teoria pode ser associada a diferentes técnicas, no caso específico destacamos o desenho e os mapas conceituais.

Este livro é constituído de um prefácio escrito pelos autores, que o apresentam na perspectiva do campo educacional, destacando as Técnicas do Desenho e de Mapas Conceituais. Vale destacar o prefácio intitulado de "Desenho e mapas: no entre-lugar da escuta" de Maria de Lourdes Soares Ornela e a seguir os capítulos denominados de "A Técnica do Desenho na pesquisa educacional sobre Representações Sociais" de Ivanilde Apoluceno de Oliveira, Waldma Maíra Menezes de Oliveira e Andréa Pereira Silveira; O uso de Mapas Conceituais na pesquisa das Representações Sociais de Huber Kline Guedes Lobato e José de Anchieta de Oliveira Bentes.

\footnotetext{
1 Mestrado em Direito, Universidade da Amazônia; Professora do curso de Direito da Universidade Estácio; Grupo de Pesquisa Infância, Cultura, Educação - UEPA. Orcid iD: http://orcid/0000.0002-0182-8905. E-mail: angelicalinsadv@gmail.com

2 Mestre em Educação - UEPA; Professora de Educação Básica - Ensino Fundamental I da Secretaria Executiva de Educação - SEDUC-PA; Grupo de Pesquisa Infância, Cultura e Educação. Orcid iD: http://orcid/000.0003-43-0100-7530. E-mail: kmariasd@hotmail.com
} 
Na apresentação destacam que o artigo sobre a Técnica do Desenho foi desenvolvido a partir dos estudos das Representações Sociais referenciada na abordagem processual de Serge Moscovici, já a técnica de Mapas Conceituais na perspectiva das Representações Sociais é uma técnica relevante que tem origem na Teoria da Aprendizagem Significativa (TAS) de David Ausubel. Em ambos os textos apresentados encontra-se presente a relevância destas estratégias metodológicas no âmbito da pesquisa educacional, na perspectiva de contribuição para a categorização e análise dos dados em pesquisa sobre Representações Sociais.

A articulação acontece pelo aporte teórico metodológico das Representações Sociais fundamentado em Serge Moscovici com a contribuição da Teoria da Aprendizagem Significativa de Ausubel.

Desta forma, os estudos sobre as estratégias metodológicas do desenho e de Mapas Conceituais em pesquisas educacionais com base na Teoria das Representações Sociais se revelam como possibilidades significativas de utilização e ineditismo na pesquisa, principalmente nas que consideram a criança como participantes principais.

A seguir, apresentamos de forma específica a constituição do livro iniciando pelo prefácio e posteriormente os demais textos. "Desenho e mapas: no entre-lugar da escuta" de Maria de Lourdes Soares Ornela destaca a relevância da obra para - pesquisador das Representações Sociais, principalmente para aqueles que pretendem utilizar como estratégias metodológicas o desenho e Mapas Conceituais. A professora destaca a presença das Representações Sociais na área de educação, o que tem contribuído para um novo olhar para os processos educativos e subjetivos no interior da escola, em especial para a utilização de estratégias de desenhos e Mapas Conceituais como recursos significativos de escuta e de representações da realidade. Enfatiza que a obra tem uma singularidade, e ressalta "que assim é o método: é necessário estar apoiado para que o pesquisador avance na pesquisa" (ORNELA, 2018, p.19). Destaca que a obra tem "fineza intelectual, olhar o que está em sua frente, trás, nas laterais, em cima e no intramuros da instituição escolar" (ORNELA, 2018, p.19). Desta forma, na sua metafórica e poética escrita destaca a importância da leitura e de forma tácita recomenda a leitura.

Em relação ao texto intitulado de "A Técnica do Desenho na pesquisa educacional sobre Representações Sociais" de Ivanilde Apoluceno de Oliveira, Waldma Maíra Menezes de Oliveira e Andréa Pereira Silveira, temos a evidenciar que se trata de uma escrita que traz em seu cerne a teoria das Representações Sociais criada por Serge Moscovici na França em 1961.

Destaca inicialmente que o texto tem sua origem em estudos realizados por Oliveira (2014) sobre a produção dos Programas de Pós-Graduação em Educação da Região Norte e se deparou com uma gama de temas trabalhados a partir das Representações Sociais. Destes, pode-se frisar segundo as autoras, sobre a educação infantil, educação de jovens e adultos, dentre outros, além de uma diversificada presença de métodos e técnicas utilizadas a partir da RS. AlvesManzzotti (2005) enfatiza que nem todos os estudos das Representações Sociais

Revista Exitus, Santarém/PA, Vol. 12, p. 01 - 06, e022010, 2022. 
apresentam uma diversidade de técnicas e estratégias, sendo que tal fato provoca um "enriquecimento" nas pesquisas de RS.

Este texto apresenta destaque para a técnica do desenho e problematiza: como se efetiva a Técnica do Desenho em pesquisas de Representações Sociais no campo educacional? (OLIVEIRA; OLIVEIRA; SILVEIRA, 2018, p.22). Nessa pesquisa é analisada a técnica do desenho na perspectiva das Representações Sociais de Moscovici. Apresenta como metodologia "pesquisa bibliográfica, por meio da qual foram selecionados os desenhos, visando classificá-los em termos de uso e de categorização de análise" (OLIVEIRA; OLIVEIRA; SILVEIRA, 2018, p. 22).

Estamos mergulhados em um mundo de imagens e discursos variados, com suas diversas formas de manifestação. Esse ato consiste na categorização, situar os acontecimentos, pessoas ou objetos em algum paradigma já estabelecido no meio social. Com isso, observamos o quão decisivo são as formas como concebemos a realidade, visto que a representação será construída a partir da base de conhecimento adquirida anteriormente, ou seja, as representações já instauradas transformam-se em ações, tornam-se realidade. A ótica de análise de qualquer sujeito, nada mais é que as imagens construídas e consolidadas na prática do cotidiano.

O texto encontra-se organizado em itens que se subdividem. O primeiro item denominado de "O uso da técnica da elaboração dos Desenhos em pesquisas educacionais sobre Representações Sociais", levanta inicialmente o que é RS na perspectiva de Moscovici, "corpus organizado de conhecimentos e uma das atividades psíquicas graças às quais os homens tornam inteligíveis a realidade física e social" (MOSCOVICl, 1978, p. 28 apud OLIVEIRA; OLIVEIRA; SILVEIRA, 2018, p. 23). Enfatiza ainda sobre a utilização da Técnica do Desenho nas Representações Sociais a partir de autores como Víctoria et al. (2000) que destaca que a utilização do desenho é importante em situações em que a comunicação oral é insuficiente; Silveira (2011) que ressalta a necessidade de planejar a produção do desenho.

Vale destacar que o pesquisador deve "solicitar ao entrevistado que desenhe suas Representações Sociais sobre alguém ou alguma coisa e em seguida explique o seu desenho, dando por fim, um nome à figura desenhada" (OLIVEIRA; OLIVEIRA; SILVEIRA, 2018, p. 25). Destarte, posteriormente, o pesquisador precisa analisar os desenhos a partir do enfatizado pelo participante da pesquisa.

As autoras evidenciam que os desenhos se representam de diferentes formas e significados e destacam: a) representar objetos com determinados significados simbólicos; b) representar ambiente de trabalho, c) representação de si e ao outro; c) representar como se sente em um determinado espaço social; d) representar movimentos de dança artística e, formas de comunicação; e) representar uma situação histórica existencial.

O outro item do texto denominado de "Processo de categorização e análise de desenhos na pesquisa em Representações Sociais", reporta a construção metodológica das pesquisas educacionais sobre RS na perspectiva da categorização e análise dos desenhos. Ressalta alguns aspectos para a estrutura de categorização. São estas: a dimensão espacial, as formas de relações, as 
expressões faciais e corporais, os pontos de destaque, os significados; a retangulação.

E finalmente as considerações finais em que destacam a dimensão epistemológica da RS; a característica multireferencial que possibilita às pesquisas educacionais diferentes abordagens teóricas, estratégias, recursos e técnicas, entre as quais o desenho. Constatam com o estudo que as representações dos sujeitos entrevistados se alinham aos dados obtidos nas entrevistas e nas observações realizadas e impactam os discursos por revelarem significados simbólicos.

O segundo texto da obra "O uso de Mapas Conceituais na pesquisa das Representações Sociais" de Huber Kline Guedes Lobato e José de Anchieta de Oliveira Bentes, destaca que a pesquisa de Representações Sociais "é um tipo de pesquisa em que há a utilização de variadas metodologias de coletas e análise de dados" (LOBATO; BENTES, 2018, p. 55).

Os autores destacam que o pesquisador da Teoria das Representações Sociais (TRS) pode organizar os "procedimentos metodológicos para a coleta de dados mediante vários recursos, tais como: observações, entrevista, associação livre ou evocações livres de palavras, grupos focais, uso de registros de imagens como por exemplo desenhos, fotografias, filmes, mapas conceituais, entre outros" (LOBATO; BENTES, 2018, p. 55-56).

Observam que os registros de imagens por intermédio dos mapas conceituais ainda são pouco utilizados no âmbito das TRS e ressaltam que "o uso desta técnica de coleta de dados enriquece, facilita e torna mais precisa a metodologia de pesquisa e potencializa as análises dos dados coletados" (LOBATO; BENTES, 2018, p. 56).

O texto apresentado é resultado de uma pesquisa realizada no Programa de Pós-Graduação em Educação da Universidade do Estado do Pará. Na pesquisa foi utilizada como estratégia para o levantamento de dados os Mapas conceituais, técnica oriunda da Teoria da Aprendizagem Significativa (TAS) capitaneada por David Ausubel.

Há um destaque dos autores acerca dos Mapas Conceituais associados a pesquisa de Representações Sociais como uma perspectiva relevante, "pois tornase uma forma do entrevistado atribuir sentido e ancorar o sentido dessas imagens ao que já conhece-tornando familiar um conceito assimilado da ciência" (LOBATO; BENTES, 2018, p. 56).

O estudo objetiva: mostrar a relevância do uso de mapas conceituais enquanto estratégia para a obtenção de dados no âmbito da pesquisa de Representações Sociais, bem como revelar os diversos e/ou variados tipos de Mapas Conceituais.

O texto ora apresentado levanta alguns aspectos conceituais sobre a representação social, tomando por base Jodelet (2001) a partir de: quem sabe e de onde sabe? O que e como sabe? Sobre o que sabe e com que efeitos? E por fim apresenta alguns modelos de Mapas Conceituais.

Conforme os estudos de Serge Moscovici, romeno, radicado na França, o termo Representações Sociais surge a partir da obra La psychanalyse, son image et son public. Na Teoria das Representações Sociais as ideias compartilhadas são parte 
da realidade, ou seja, a forma com a qual determinado fato é mostrado ao grupo que vai produzir uma representação na perspectiva do já habitual, pois são conhecimentos oriundos das relações. Neste sentido, essa produção está sempre em consonância com a intencionalidade daquele que o produz. No que concerne a essa intenção do sujeito, este está sempre inserido em um contexto, o que implica pensar em um contexto com as suas especificidades, assim, esse conhecimento produzido vai ser oriundo dessas circunstâncias e contexto. Destarte, as RS "são fenômenos que necessitam ser descritos e explicados, como um modo que cria tanto a realidade como o senso comum, um modo de compreender $e$ de comunicar na vida cotidiana" (LOBATO; BENTES, 2018, p, 58).

Por isso, todo conhecimento não é desinteressado, pois o mesmo não está imune aos interesses dos produtores. Desta forma, a Representação Social é uma teoria imprescindível para a constituição das interações sociais. Essas interações são notadamente marcadas por um fator social mais abrangente, o qual se consolida em um meio específico, por conseguinte "precisam ser visualizadas como uma legítima teoria do senso comum elaborada a partir da interpretação ou compreensão dos universos sociais" (LOBATO; BENTES, 2018, p. 59).

No que se refere a essa perspectiva social, as representações sociais estão relacionadas às mudanças de interesses de seus agentes, visto que os interesses deixam de ser os mesmos quando surgem diferentes formas de usar a palavra. Esse comunicar vai perpassar por uma inovação, o qual irá desencadear um interesse diferente, ou seja, uma nova representação a respeito de determinado fato ou objeto. "Assim, entendemos que as RS são construções objetivas e subjetivas elaboradas nos processos de comunicação e interação de um determinado grupo social" (LOBATO; BENTES, 2018, p. 63).

O item seguinte aborda sobre "A pesquisa de Representações Sociais", momento em que destaca que a pesquisa ora apresentada fundamenta-se em uma abordagem qualitativa (MINAYO, 1994, p. 21), e desenvolvida com base na metodologia de pesquisa das Representações Sociais e como mecanismo utiliza a ancoragem e objetivação na perspectiva de identificar como os conceitos são ancorados e objetivados em ideias e percepções pelos participantes da pesquisa.

Adotaram a partir de Jodelet (2001) a abordagem processual e como estratégias metodológicas os eixos: "quem sabe e de onde sabe? O que e como sabe? Sobre o que sabe e com que efeitos?" (LOBATO; BENTES, 2018, p.65). Estes questionamentos estão articulados durante todo o trajeto da pesquisa, associado ao uso dos Mapas Conceituais, observações e entrevistas.

O item seguinte denominado de Mapas Conceituais evidencia que estes são oriundos da Teoria da Aprendizagem Significativa de Ausubel. Ressaltam que "a aprendizagem significativa ocorre quando um novo saber é influenciado a partir dos conhecimentos prévios adquiridos anteriormente, ou seja, aquilo que o sujeito já sabe" (LOBATO; BENTES, 2018, p. 68-69). Os Mapas Conceituais segundo Tavares (2007) são do tipo, teia de aranha; fluxograma; sistema entrada e saída; e hierárquico; Cmap Tools. A seguir destacamos cada um dos MC.

1) Teia de aranha - é um mapa em que parte de um conceito central ou gerador que se encontra no meio do mapa; 
2) Fluxograma - a ideia encontra-se organizada a partir de um critério de linearidade de informações, onde percebemos que existe um ponto inicial e final nas informações o que favorece a compreensão de determina temática;

3) Sistema entrada e saída - organiza os conceitos em um formato de informações em que há correlação, sem obedecer a uma sequência linear em relação às informações;

4) Hierárquico - o conceito geral encontra-se na parte superior e os conceitos mais específicos e/ou secundários na parte inferior;

5) Cmap Tools - constitui-se em softwares para a construção e compartilhamento de Mapas Conceituais por meio do uso do computador.

E finalmente destacam que a utilização de mapas conceituais contribui para a pesquisa de Representações Sociais e enriquece as falas dos entrevistados e potencializa os resultados finais por meio de imagens, como ferramenta didática e principalmente no uso de pesquisa de Representações Sociais.

Com base no evidenciado destacamos que a obra é de significativa relevância para pesquisadores da área das Representações Sociais e uma possibilidade de motivar a incursão de outros pesquisadores das diversas áreas, que estudam ou pretendem pesquisar tomando como referencial teórico metodológico as Representações Sociais. Enfatizamos que os desenhos, bem como os Mapas Conceituais, são estratégias que vem sendo utilizadas de forma recorrente nas pesquisas em que as infâncias e as crianças são os participantes principais. Vale ressaltar que as representações dos participantes das pesquisas por meio de entrevistas e observações se evidenciam no expressado nos desenhos e Mapas Conceituais.

A obra fornece indicadores consistentes de novos cenários educacionais com base em novos pressupostos teórico-metodológicos das Representações Sociais. O apresentado reflete possibilidades de percursos investigativos articulados, voltados às várias temáticas associadas às TRS. Assim sendo, aponta caminhos e possibilidades para a pesquisa no campo educacional e aponta cenários investigativos em que elementos teóricos são associados e articulados a uma nova perspectiva metodológica intrínseca aos conhecimentos da TRS, permitem potencializar ações, que se materializam em práticas sociais e educacionais. Estas ações convergem não apenas no desenvolvimento de estratégias e técnicas de pesquisa, mas também geram a possibilidade de criar, inovar e produzir conhecimentos novos, para a pesquisa educacional.

Recebido em: 12 de setembro de 2021. Aprovado em: 20 de dezembro de 2021.

Publicado em: 08 de janeiro de 2022. 